\title{
PR-56
}

\section{MODELING THE ANTITUBULIN ACTIVITY OF BENZIMIDAZOL-2-YL CARBAMATES: MINI-REVIEW}

\author{
$\underline{\text { K. L. Obydennov }}{ }^{1}$ O. N. Kanwugu, ${ }^{1}$ T. A. Kalinina, ${ }^{1}$ T. V. Glukhareva ${ }^{1,2}$ \\ ${ }^{1}$ Ural Federal University of the first President of Russia B. N. Yeltsin, \\ 19 Mira St, Yekaterinburg, 620002, Russia. \\ ${ }^{2}$ I.Ya. Postovsky Institute of Organic Synthesis UB RAS, \\ 20/22 S. Kovalevskoy/Akademicheskaya St, Yekaterinburg, 620990, Russia. \\ E-mail: k.l.obydennov@urfu.ru
}

\begin{abstract}
Computer modeling has become the commonly used method to explain biological activity of substances [1]. Despite the technical attractiveness of this approach, there are serious difficulties in creating a theoretical model that would correspond to the experimental data [2]. The purpose of this mini-review is to systematize scientific efforts to predict the binding site of benzimidazol-2-yl carbamate derivatives with $\beta$-tubulin. Interest in the generalization of these studies is due to the fact that while the crystal structure of the complex tubulin with methyl [5-(2-thienylcarbonyl)-1H-benzimidazol2-yl] carbamate 1 was published only in 2015 (PDB id 5CA1, Figure 1), some details of the interaction of benzimidazol-2-yl carbamates with $\beta$-tubulin could be predicted before it. This mini-review summarizes the results of such works.
\end{abstract}

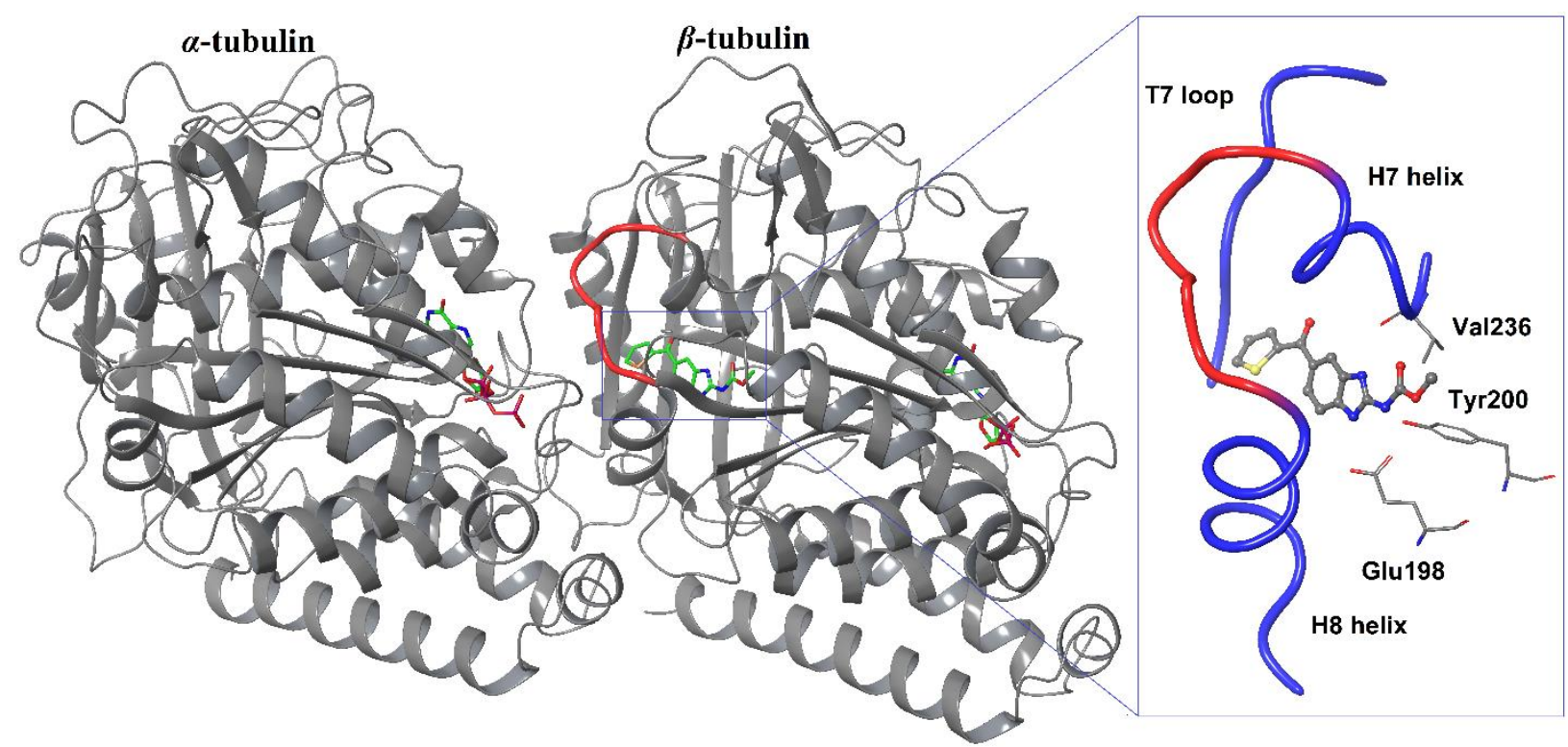

Figure 1. Nocodazole complex with tubulin (PDB id 5CA1).

\section{References}

1. Sarkar A. A Comparative Analysis of the Molecular Interaction Techniques for In Silico Drug Design / A. Sarkar, S. Sen // International Journal of Peptide Research and Therapeutics. - 2020. - Vol. 26, Iss. 1. - P. 209-223.

2. Y.-C. Chen, Trends in Pharmacological Sciences. - 2015. - Vol. 36, Iss. 2. - P. 78-95.

This research was supported by the Russian Foundation for Basic Research (grant No. 18-316-20018). 